\title{
ABBAS UMAROVICH UMAROV
}

(1928-1993)

The scientific community has suffered a heavy loss by the untimely death of the scholar-chemist, Doctor of Chemical Sciences, Professor A. U. Umarov.

A. U. Umarov was born on November 11, 1928 into an office-worker's family. After graduating from the Central Asian State University, Abbas Umarovich began post-graduate study at the Institute of the Chemistry of Plant Substances, Academy of Sciences of the Republic of Uzbekistan, under the well-known specialist on lipid chemistry and technology, Prof. A. L. Markman. From this time his scientific investigations were devoted to the study of the lipids of the wild-growing flora of Central Asia and to the improvement of the technology of the oils and fats industry.

In 1960 he defended a dissertation for the award of the scientific degree of Candidate of Chemical Sciences. He was one of the organizers of the laboratory of lipid chemistry in the Institute of the Chemistry of Plant Substances, Academy of Sciences of the Republic of Uzbekistan, and was its permanent director for almost a quarter of a century. He devoted great attention to the development of fundamental investigations in lipid chemistry. The results of his applied work enabled additional products for the national economy to be obtained from cotton seeds. The results of many years' investigations formed the basis for his Doctoral dissertation, which he defended in 1977. In 1983, Prof. A. U. Umarov moved to Samarkand, where he founded the chemistry department in the cooperative institute while continuing his scientific activity in the field of the chemisty of plant lipids. A number of Candidates' dissertations were prepared and defended under his direction.

By his self-sacrificing service to science and higher education and by his human qualities, Abbas Umarovich won deserved esteem and authority among the chemists of Uzbekistan. The investigations continuing after him will always remind us of his contribution to science.

The bright memory of Abbas Umarovich will remain for ever in the hearts of those who knew him.

Translated from Khimiya Prirodnykh Soedinenii, No. 3, p. 450, May-June, 1994. 